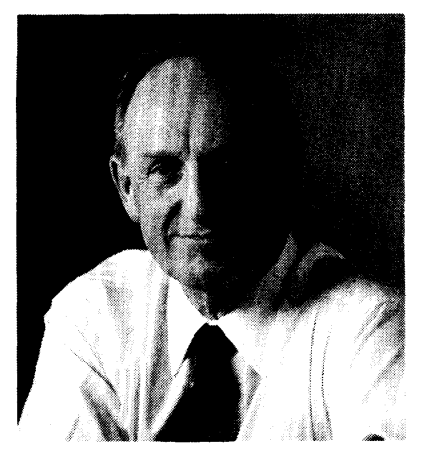

\section{Optical Engineering Readers: We Got Your Input}

Earlier this year we mailed out a carefully constructed questionnaire to all our readers. It was entitled "Optical Engineering Readers: We'd Like Your Input." Indeed, we did receive your input with approximately one thousand direct written responses as well as oral responses. We appreciate the feedback since it will help your society to plan the future of Optical Engineering. We must say as your Editor and Managing Editor, respectively, that we thank you for your response to the questions and your additional written comments. You made us feel good about what Optical Engineering has accomplished even though we fully recognize that we can do even better. It is important that we share with you, the readers, a summary report of the survey; hence in this editorial and the next we will share with you your collected input unrationalized by our editorial presence.

The following bullets summarize the 981 responses to the survey questions, which will give you some sense of the collective impressions and attitudes of the readers (users) of Optical Engineering:

- Approximately $52 \%$ agree that OE's growing size and broad scope serve their needs and would like to see it continue to be published once a month with an unlimited page count. Approximately $44 \%$ disagree.

- Approximately $25 \%$ find four to six papers a month of interest; approximately $65 \%$ find one to three of interest.

- Approximately $75 \%$ refer to $\mathrm{OE}$ one to three times a month.

- Approximately $85 \%$ recommend OE to a colleague to read a paper every month or occasionally, while $15 \%$ never do.
OE's growing size and broad scope serve my needs. Therefore, it should continue to be published once a month with an unlimited page count.

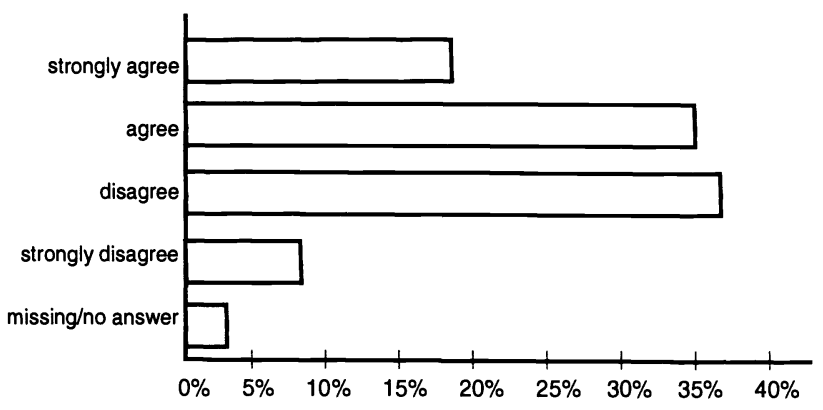

My needs would be better served if ...

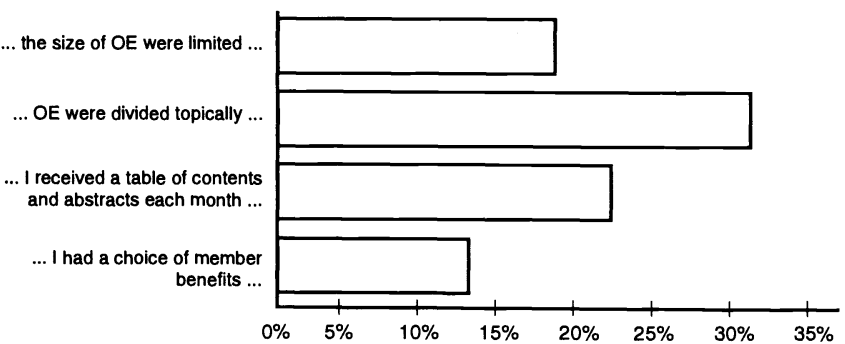

What number of papers in each issue, on average, are of interest to you?

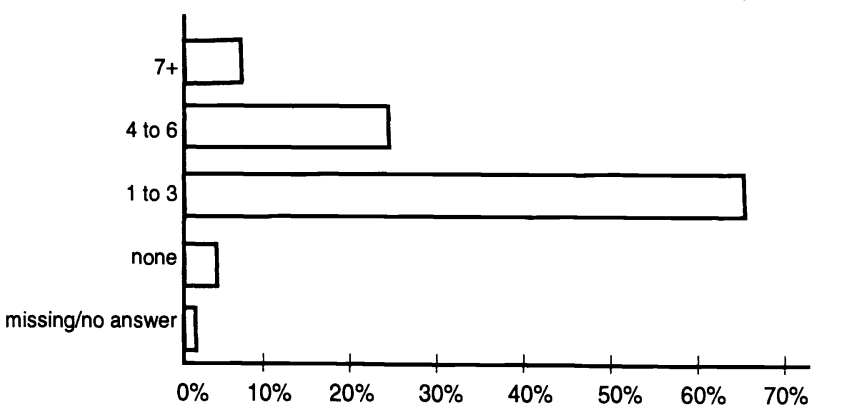


How many times do you refer to OE on a monthly basis?

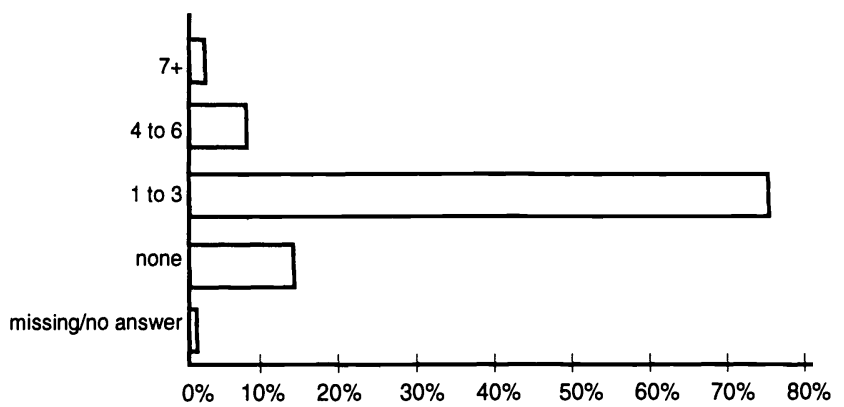

How often do you pass on your copy of OE to a colleague?

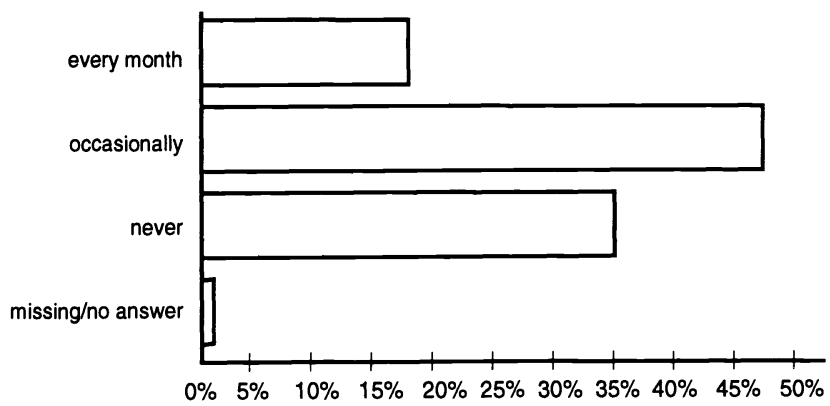

How often do you recommend $O E$ to a colleague to read a paper?

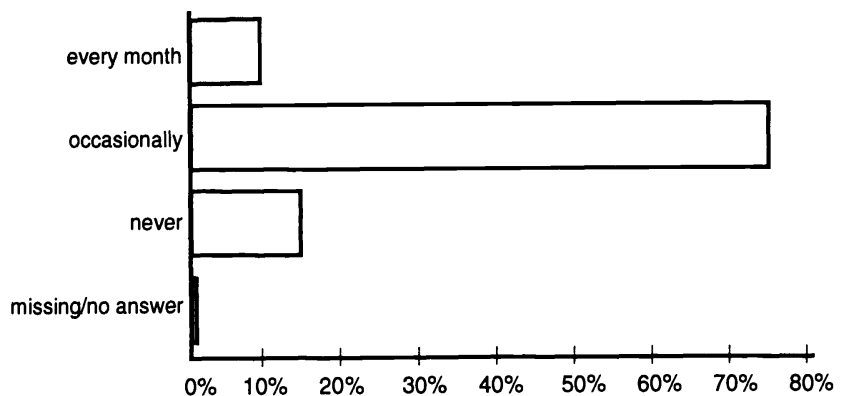

- Approximately $87 \%$ feel the regular inclusion of special sections adds value and interest to the journal.

- Approximately $49 \%$ say receiving OE is their principal reason for being an SPIE member; approximately $50 \%$ say it's not.

- Approximately $88 \%$ say the papers are of good quality.

- Approximately $81 \%$ are primarily interested in applications-oriented papers, while approximately $36 \%$ are interested in basic research/theory type papers. (Numbers skewed because some answered as having primary interest in both types.)

- Approximately $51 \%$ would like to see an electronic version of OE offered along with the print version, but only approximately $22 \%$ would go for just the electronic version.

- Approximately $87 \%$ consider OE a primary or secondary reference.

The basic data from which these conclusions are drawn are the nine questions asked in the questionnaire. The accompanying graphs show the actual percentage response to the first five questions.

Stay tuned; next time we will give you the raw data on the rest of the questions.

Brian J. Thompson Editor

Lorretta Palagi Managing Editor 
October 1994

\section{Optics in Russia}

V. Ya. Panchenko

Scientific Research Center for Technological Lasers

Russia Academy of Sciences

B-333, Gubkina, 3

117971 Moscow, Russia

E-mail: ilc@ compnet.npimsu.msk.su

(095)135-54-30 • (095)334-02-01 FAX

Digital Image Recovery and Synthesis

Paul S. Idell

Rockwell International

Rocketdyne Division

MS SS46

P.O. Box 7922

Canoga Park, CA 91309-7922

818/586-8238 • 818/586-5295 FAX

E-mail: pidell@windance.rdyne.rockwell.com

\section{November 1994}

\section{Micro-Optics}

Chandrasekhar Roychoudhuri

University of Connecticut at Storrs

Photonics Research Center

MS-157, Room 312

260 Glenbrook Road

Storrs, CT 06269-3157

203/486-4816 • 203/486-3789 FAX

\section{December 1994}

\section{Optics in Ireland}

John Hegarty

University of Dublin

Trinity College

Department of Pure and Applied Physics

Dublin 2, Ireland

+353-1-7022019 • +353-1-711759 FAX

Conleth D. Hussey

University of Limerick

Lightwave Technology Research Ctr.

Plassey Pk.

Limerick, Ireland

$35261333644 \cdot 35261330316$ FAX

\section{February 1995}

High Heat Flux Optical Engineering

Ali M. Khounsary

Argonne National Laboratory

Advanced Photon Source, APS 362

Argonne, IL 60439

$708 / 252-3384$ • 708/252-3222 FAX

\section{March 1995}

Optical Engineering in Ophthalmology

Suganda Jutamulia

Kowa Company, Ltd.

Silicon Valley Office

100 Homeland Court, Suite 302

San Jose, CA 95112

408/441-9300 • 408/441-0537 FAX

Toshimitsu Asakura

Hokkaido University

Research Institute for Electronic Science

Sapporo, 060 Japan

81-11-716-2111 • 81-11-758-3173 FAX

\section{April 1995}

Optics in the Ukraine

Oleg V. Angelsky

Chernovtsy University

Department of Correlation Optics

2 Kosyubinsky Street

274012 Chernovtsy

Ukraine

(03722) 44730 • (03722) $41314 \mathrm{FAX}$

May 1995

\section{X-Ray/EUV Optics}

Richard B. Hoover

NASA Marshall Space Flight Center

ES52 Space Science Center

Huntsville, AL 35812-0001

E-mail: hoover@ssl.msfc.nasa.gov

205/544-7617 • 205/544-5856 FAX

July 1995

\section{Optics in Switzerland}

P. K. Rastogi

Swiss Federal Institute of Technology-Lausanne

Laboratory of Stress Analysis

CH-1015 Lausanne

Switzerland

E-mail: rastogi@elgc.epfl.ch

(021) 6932445 • (021) 6934748 FAX

Manuscripts due Nov. 15, 1994

\section{September 1995}

Optical Science \& Engineering in Finland

Seppo Honkanen

Nokia Research Center

P.O. Box 45

FIN-00211 Helsinki

Finland

+358 $04376471 \bullet+35804552557 \mathrm{FAX}$

Manuscripts due Jan. 15, 1995

November 1995

Optical Remote Sensing and Image

Processing

Mohammad A. Karim

Bradley D. Duncan

University of Dayton

Center for Electro-Optics

300 College Park

Dayton, OH 45469-0227

513/229-2241 • 513/229-3177

513/229-2471 FAX

Manuscripts due April 1, 1995

\section{December 1995}

Optics in Polymer Science and Technology

Maksymilian Pluta

Institute of Applied Optics

Kamionkowska 18

03-805 Warsaw, Poland

(4822) $184405 \cdot(4822) 133265$ FAX

Andrzej Wasiak

Institute of Fundamental Technological Research

Polish Academy of Sciences

Savietokrzyska 21

00-012 Warsaw, Poland

(4822) 269815 FAX

Manuscripts due April 1, 1995.
January 1996

Optical Science and Engineering in Argentina

Guillermo H. Kaufmann

Universidad Nacional de Rosario

Instituto de Fisica Rosario

Applied Optics Group

Bv. 27 de Febrero 210 bis

2000 Rosario

Argentina

E-mail: guille@ifir.edu.ar

or gkaufman@ arosario.bitnet

5441825838 • 5441257164 FAX

Manuscripts due June 1, 1995

Visual Communications and Image Processing

Cheng-Tie Chen

Bellcore, NVC 3X-321

331 Newman Springs Road

Red Bank, NJ 07701

908/758-3106 • 908/758-4371 FAX

E-mail: ctc@nyquist.bellcore.com

Kou-Hu Tzou

COMSAT Laboratories

22300 Comsat Drive

Clarksburg, MD 20871

301/428-4663 • 301/428-9287 FAX

E-mail: kouhu@ctd.comsat.com

Ya-Qin Zhang

GTE Laboratories

40 Sylvan Road

Waltham, MA 02254

617/466-2259 • 617/890-9320 FAX

E-mail: yz00@gte.com

Manuscripts due June 1, 1995

\section{February 1996}

Optical Engineering in Small Companies

Xiangyang Yang

Quantex Corporation

2 Research Court

Rockville, MD 20850

301/258-2701 • 301/258-9871 FAX

William J. Miceli

Office of Naval Research

800 North Quincy Street

Arlington, VA 22217-5000

703/696-5752 • 703/696-1330 FAX

Manuscripts due July 1, 1995

\section{March 1996}

Sensor Fusion

Belur V. Dasarathy

Dynetics, Inc.

P.O. Box Drawer B

Huntsville, AL 35814-5050

$205 / 922-9230$ ext. $355 \cdot 205 / 922-9219$ or

205/922-9260 FAX

E-mail: belur@dynetics.com

Manuscripts due Aug. 1, 1995 